\title{
استخدام طريقة الحفظ من خلال القصة المتقاطعة لترقية قدرة التلاميذ على كتابة الآيات في مادة القرآن والحديث
}

\author{
نيلفاويتا \\ جامعة السلطان الشريف قاسم الإسلامية الحكومية رياو، اندونيسيا \\ witanelva@gmail.com
}

ملخحّص

كان هذا البحث مؤسسا على انخفاض قدرة التلاميذ على كتابة الآيات التي تم دراستها. وعادة ما تكون هذه الصعوبة بسبب عدم حفظها من الآيات. وإذا تم حفظ التلاميذ الآيات وفقا لمخرجها فصاروا أسهل لكتابتها. لذلك أرادت الباحثة تطبيق هذه الطريقة لجعلها مسهلة في حفظ آيات القرآن وكتابتها. وفي هذا البحث، فإن صياغة المشكلة هي "كيفية استخدام طريقة حفظ القرآن من خلال القصة المتقاطعة في دراسة القرآن والحديث بالمدرسة الثانوية الإسلامية الحكومية الأولى بكنبارو؟" ويهدف هذا البحث إلى التعرف على استخدام طريقة حفظ القرآن من خلال القصة المتقاطعة في دراسة القرآن الكريم والحديث الشريف. والنوع من البحوث هو بحث ميداني (field research)، البحث النوعي الذي هو وصفي. وكان الفرد من هذا البحث هو المدرس في مادة القرآن والحديث، والتلاميذ، ورئيس المدرسة. وأساليب جمع البيانات المستخدمة هي الملاحظة، والمقابلة، والتوثيق. وأظهرت نتيجة البحث أن استخدام طريقة حفظ القرآن الكريم من خلال القصة المتقاطعة الإعلامية في دراسة القرآن والحديث في الصف الحادي عشر "الباء" و "الجيم" هو وفقا لخطوات استخدام القصة المقاطعة الإعلامية، وتظهر النتيجة أن الطفل يحفظ بسرعة أكبر ويهتم بحفظ القرآن والحديث.

الكلمات الأساسية : طريقة حفظ القرآن، والوسيلة، والقصة المقاطعة. 


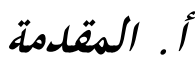

إنه لمن ابتحٍٍ جديدٍ في عالم الابتكار التربوي، وخاصة في التعليم النشيط أن التعلم ليس نتيجة

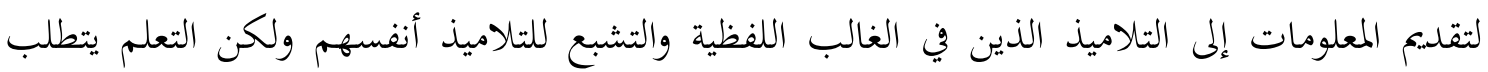

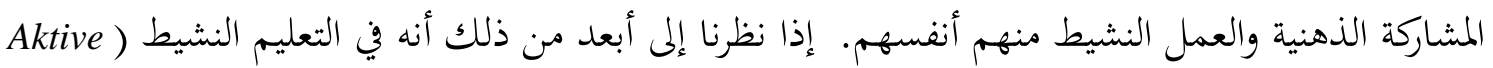

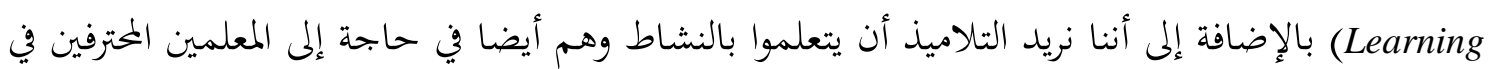

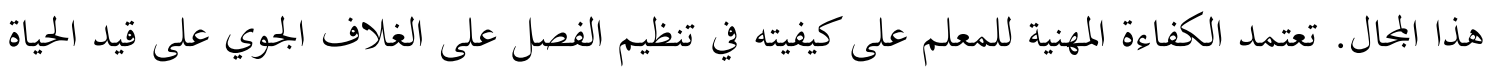

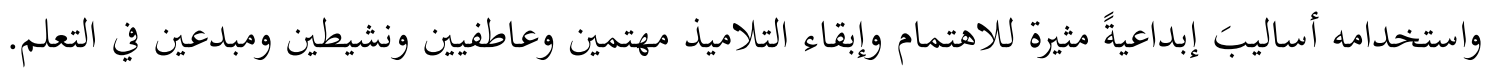

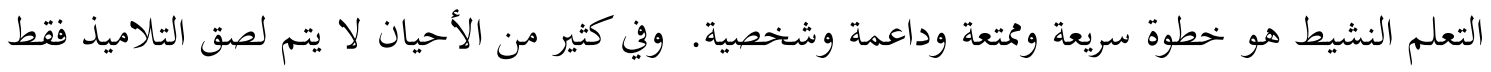

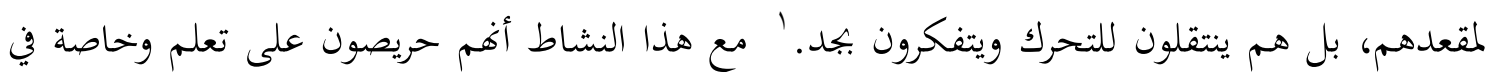

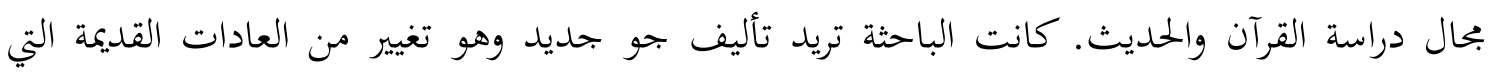

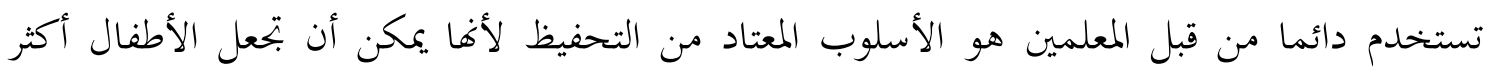

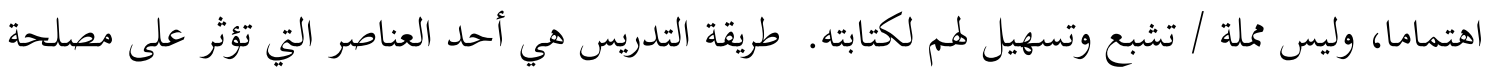
التلاميذ وإبحازهم. الطريقة مهمة جدا في تسليم المواد التعليمية كما قال ويرانتو سورخمد :

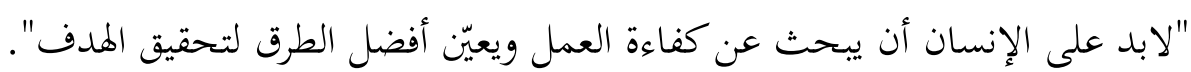

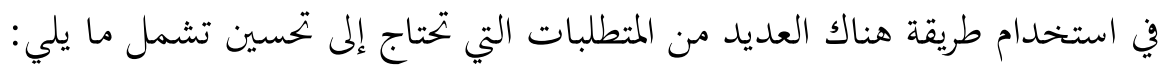

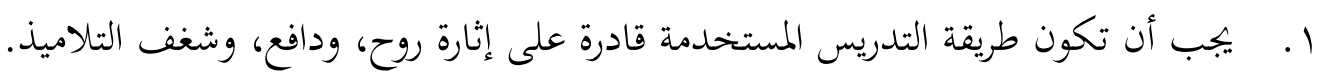
r. ب بيب أن تكون طريقة التدريس المستخدمة قادرة على التثقيف في وسائل الإعلام وتقنيات التعلم الخخاصة وكيفية اكتساب المعرفة من خلال الأعمال التجارية الخاصة.

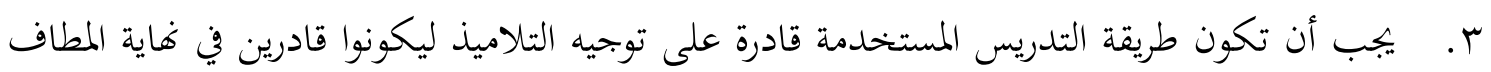
على الوقوف من تلقاء أنفسهم. وبالتالي يمكن أن يكون مفهوما أن قدرة المعلمين على استخدام أساليب التدريس من المتوقع خصوصا في طريقة تدريس القرآن والحديث.

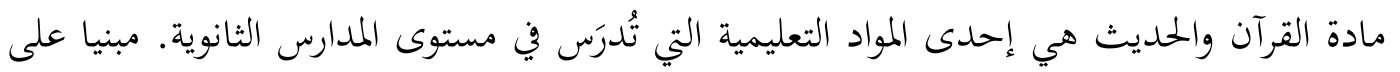

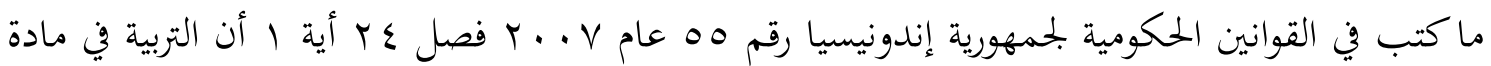

'Mel Siberman, Aktif Learning '.' Strategi Pembelajaran Aktif, Yogyakarta: YAPPENDIS Yayasan Pengkajian dan Pengembangan Ilmu Pendidikan Islam, $r \cdots r$, hal xviii

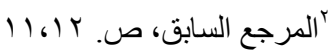


القرآن والحديث تحدف إلى ترقية قدرة التلاميذ على قراءة آيات القرآن والأحاديث وكتابتها والفهم عنها والعمل بها.

هناك طرق كثيرة يمكن استخدامها في تعليم القرآن والحديث، منها طريقة الحفر، وطريقة التعلم

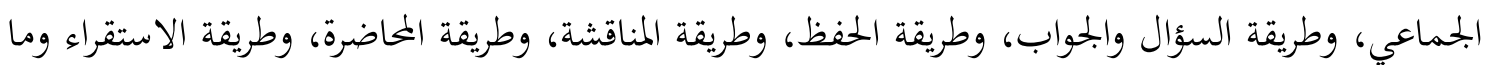

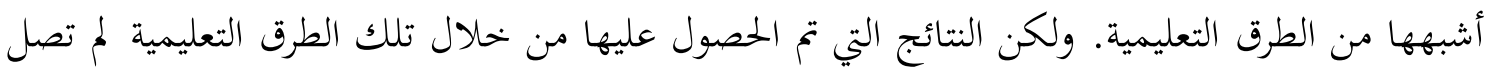

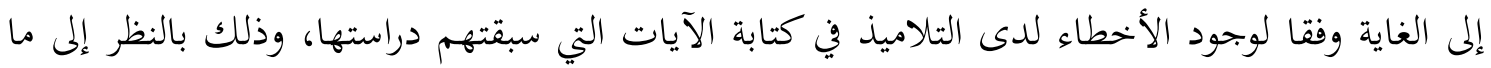

1. أن التلاميذ لم يستطيعوا الكتابة بصحتها.

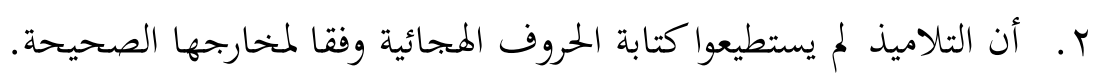
r. لا يمكن للتلاميذ كتابة آيات طويلة

ولكتابة الآيات التي تم دراستها التلاميذ يجب عليهم إتقان أو حفظ تلك الآية. ومن خلاتلال التال الحفظ

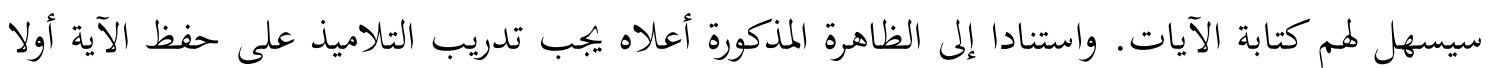
وبعد ذلك أفم قادرون على الكتابة بشكل جيد. ومن الأساليب العديدة لتدريس القرآن الكريم، طريقة الحفظ هي طريقة إديلد أكثر استخداما من قبل المعلمين في

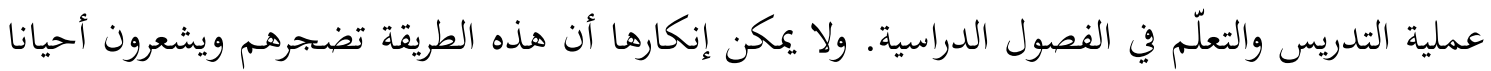
إلى مضطر الحفظ، وعادة خائفين من المعلم أو من الخغفاض القيمة.

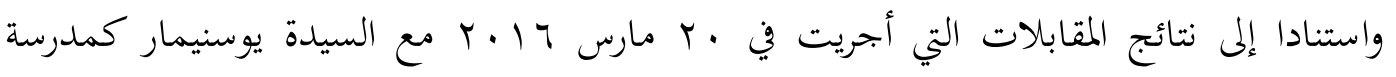

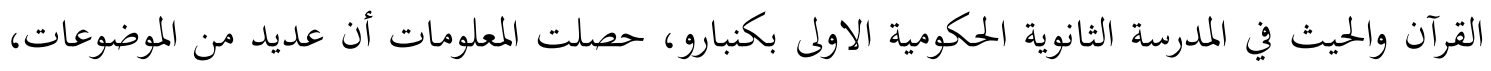

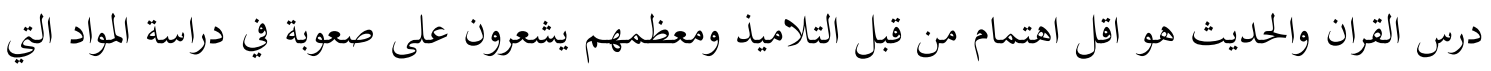

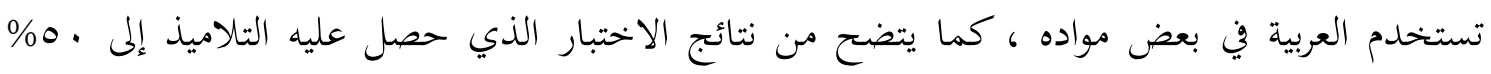

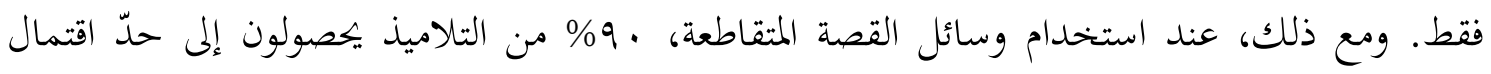

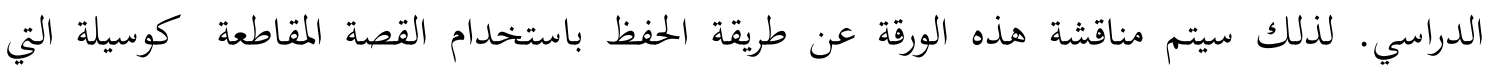

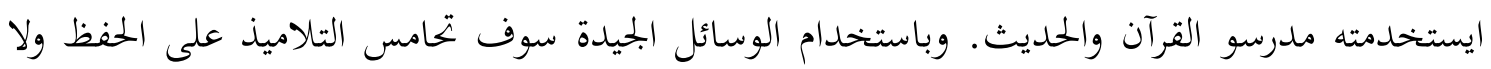
يملهم وسهولة في تنفيذها.

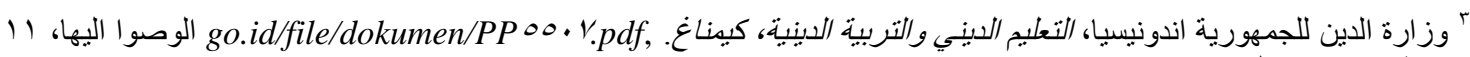

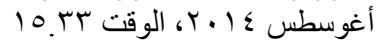


ولعلاج تلك المسئلة، استخدمت الكاتبة وسائل القصة المتقاطعة وهي من احدى التقنية لتسهيل

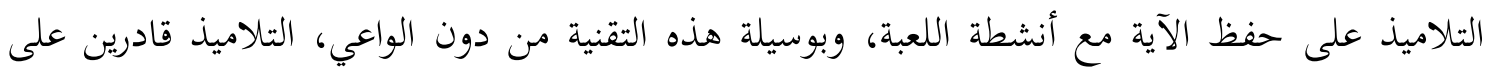

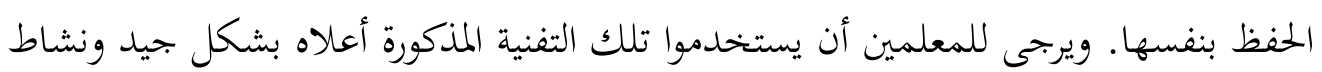

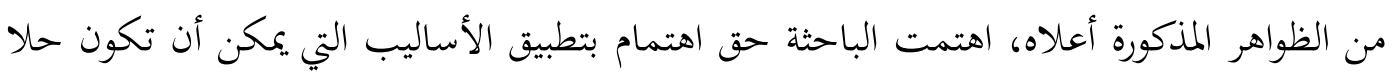

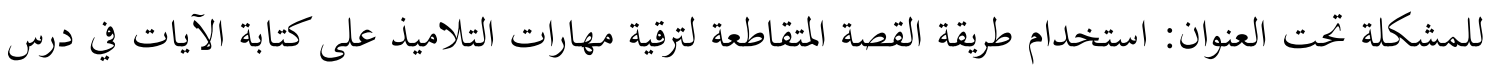

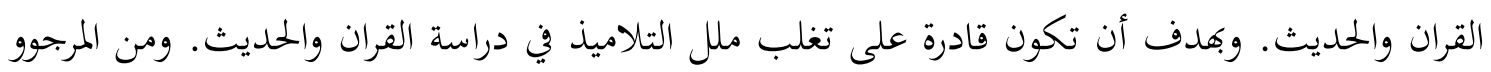
هذا البحث يمكن أن ترقي مهارات التلاميذ في كتابة الآيات ويمكن أن ترقية نتائج تعلمهم ولتحقيق تلفيق

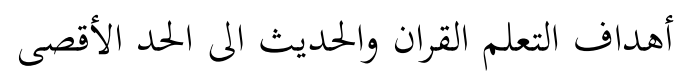

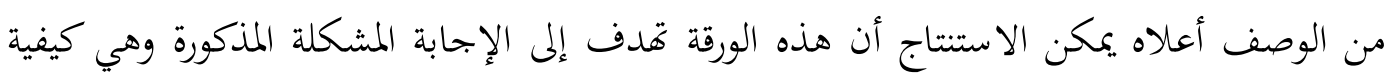

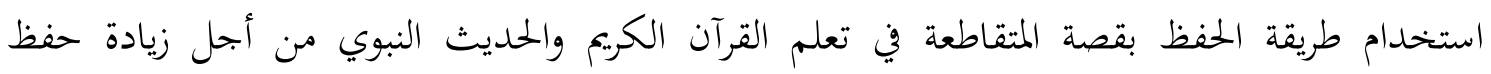

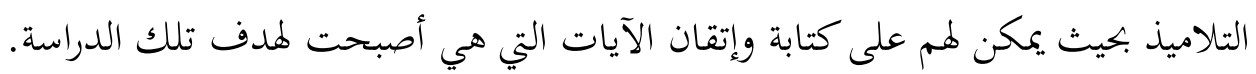

\section{الباء. استعراض المراجع الماءع}

أما المقصود من استعراض المراجع هو التعبير إلى تقديم النظريات ذات الصلة بالمشكلة التي يتعين

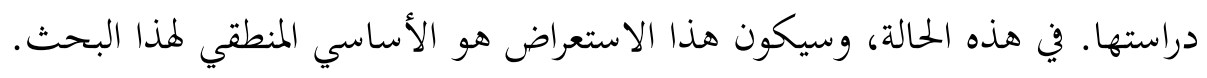

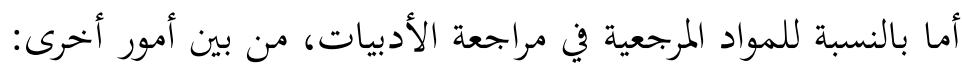

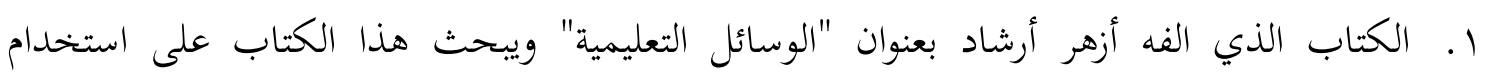

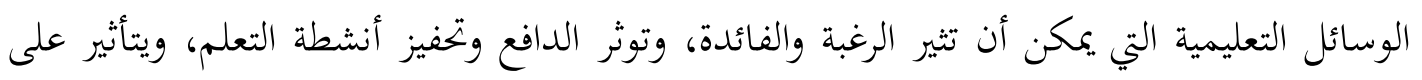

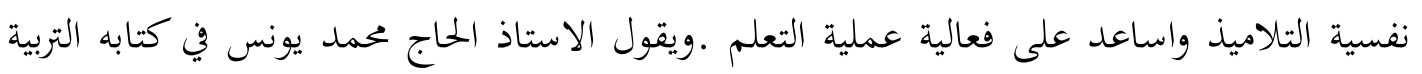

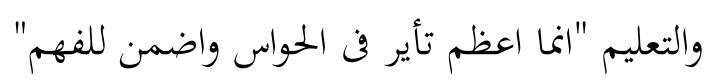

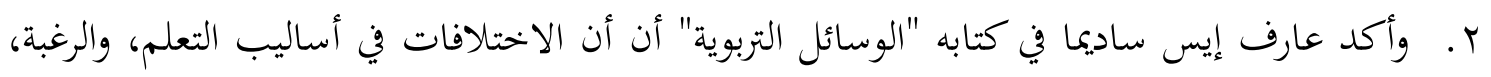

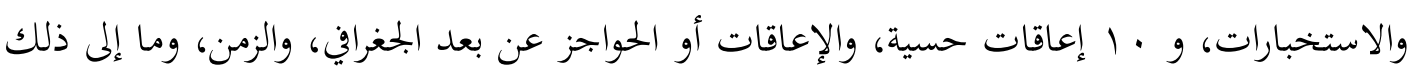
يمكن أن يساعده باستخدام وسائل التربوية.

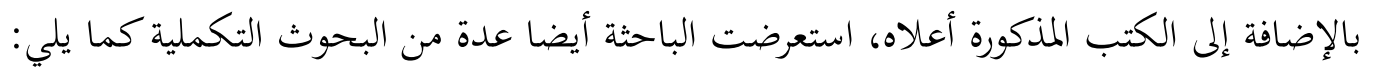

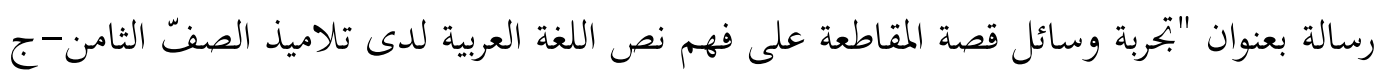

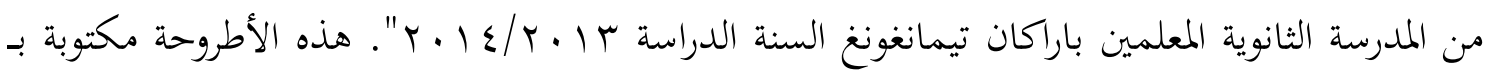

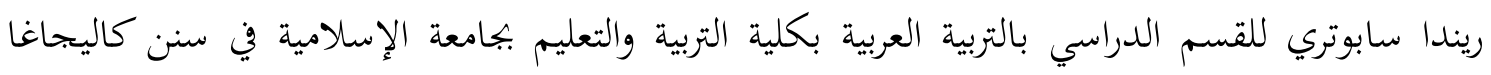

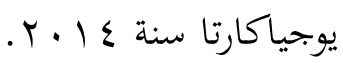


هذا البحث هو بحث كمي باستخدام البحث التجربي مع تصميم الاختبار القبلي والبعدوي بحموعة تصميم السيطرة. وأثبتت النتائج أن استخدام وسائل القصة المتتاطعة يمكن أن ترقي مهارات التلاميذ على القراءة وفهم النص وثروة اللغة ويمكن ايضا أن ترقي دوافع التعلم لدى التلاميذ في درس القراءة (المطالعة) ورسالة بعنوان "فعالية استخدام وسائل القصة المقاطعة لترقية مهارات القراءة في معهد دار السلام سوكاليلا جاتيبارانغ إندرامايو جافا الغربية ". تح كتابة هذه الرسالة بقلم لطيفة، طالبة لطبقة الماجيستير

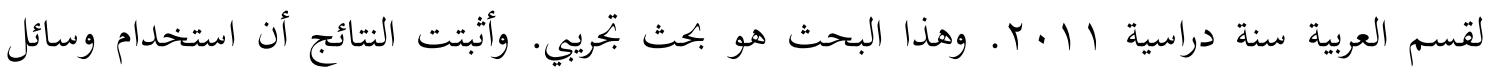
القصة المتقاطعة يمكن أن ترقي مهارات التلاميذ على القراءة وفي فهم النص وثروة اللغة ويمكن أن ترقي دوافع التعلم لدى التلاميذ في الدرس القراءة (المطالعة) رسالة بعنوان "محاولة ترقية حفظ التلاميذ باستخدام وسائل التعليم القصة المقاطاعة في درس القرآن الكريم. هذا البحث كتبته مغفرة حسنة، كلية التربية بالجامعة الإسلامية الحكومية سيمارانج في عام E. T.

ويستخدم هذا البحث عمل الفصول الدراسية من حيث ترقية الحفظ لدى التلاميذ في مادة القرآن والحديث من خلال القصة المقاطعة في الصف السابع، وأظهرت النتائج أن هناك ترقية الحفظ لدى التلاميذ من خلال استخدام وسيلة التعليم بالقصة المقاطعة مع نتائج الإجراءات المحسنة للدورة الأولى وهي نتيجة ترقية الحفظ لدى التلاميذ بمعدل الاختبار النهائي بقدر Y.97. بينما في دورة الثانية بعد تقييم التنفيذ في الدورة الأولى أصبحت النتائج ترقت في معدل الاختبار النهائي بقدر م.VY.

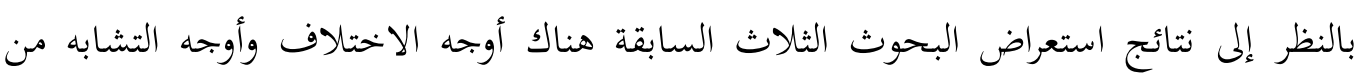
بحث الباحثة الحاضرة، حيث كان فيها وجه التشابه وذلك عن استخدام القصة المقاطعة كوسيلة التعليم، وأما وجه الاختلاف في البحث الأول الذي قامت به ريندا سافوتري بالمدرسة المتوسطة الإسلامية "المعلمين" بباراكن تيمابحجونج عن تأثير بتربة وسيلة القصة المقاطعة على فهم النص العربي بالرغم أن الباحثة الحاضرة قامت بالبحث عن استخدام طريقة الحفظ بوسيلة القصة المقاطعة لترقية قدرة التلاميذ على بلى بلى كتابة الآيات في مادة القرآن والحديث الذي هو مختلف من البحث السابق. أ. فضيلة قراءة القرآن وحفظه

القرآن "لهو الكتاب النهائي الذي أنزله الله سبحانه وتعالى، وهو يشمل على النقاط الشرعية والقوانين الواردة في الكتب المقدسة التي أنزلت من قبل. لذلك كل من يؤمن ما في القرآن يشتد حبّه إياه،

ع مغفرة حسنة، محولة لترقية الحفط لدى التناميذ باستخدام وسائل التعليم القصة الماقاطعة في درس القران والحديث، سيمار اتج، 11 . r،

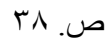


إما في تلاوته، وفي فهم معاني آياته، والتعلم عنه للعمل به حتى تعممت النعم والرحمة بالتساوي لقبل سكان الكون.

القرآن هو الأساس الأول الأعلى لأحكام الإسلام، وأما الحديث فهو تفسير وبيان عما ورد في

القرآن الكريم وينبغي على كل من المسلمين أن يتعلمه منذ صغره. ' ونحن نرى في أيامنا الحاضرة ترقية وعي لإي المسلمين واهتمامهم ورغبتهم في حفظ القرآن الكريم، وذلك بالنظر إلى ظهور عدة الحفاظ. حفظ آيات

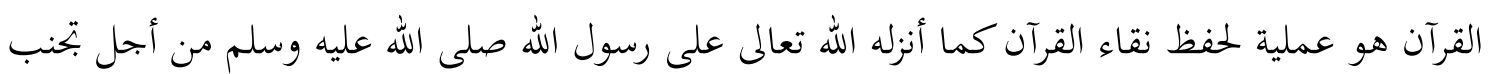
التغيير والتزوير ويمكن أن يبقي من النسيان كليا أو جزئيا. وذهب الإمام النواوي أن حكم حفط القرآن فرض الكفاية كما أن العلوم الشرعية التي لابد للمسلمين من الحصول عليها حتى يقيموا بها دينهم بالكمال. وفرض الكفاية هو الفرض الذى إذا قام به فرد واحد كفى عن الاخرين وسد عنهم ولكن اذا لم يقم به احد اثموا جميعا. ويتميز من قام بفرض الكفاية على من قام بفرض العين لأنه يسقط ذنوب الآخرين الذين لم يقوموا به. وقال إمام الحرمين في كتاب الغيائي بأن فرض الكفاية أفضل من فرض العين بالنظر إلى أنه يأتي لمصلحة الآخرين وأما فرض العين يأتي لمصحة الفرد وحده. ومن فضائل حفظ القرآن هي كما يلي : ا. أن القرآن يشفع من تلاه وحفظه وعمل به يوم القيامة لقوله صلى الله عليه وسلم :

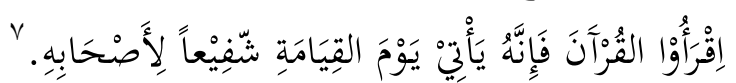

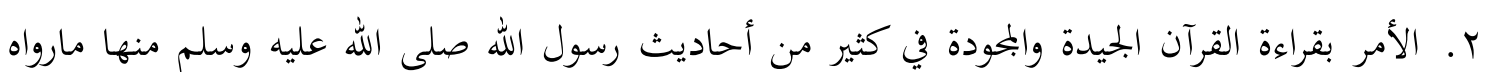

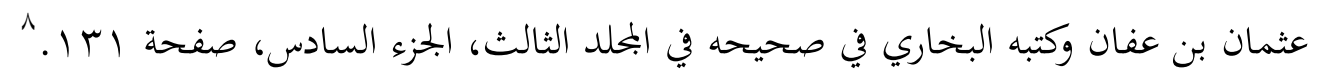

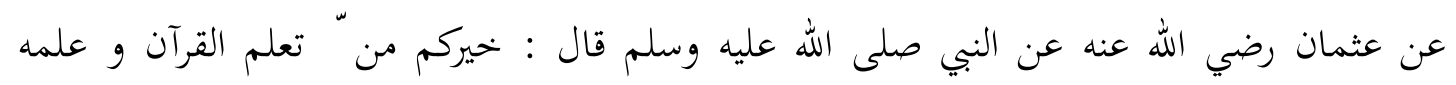

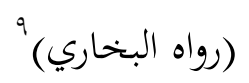

ب. حفاظ القرآن كانوا في الصفوف الأولى في الدنيا والآخرة لقوله النبي صلى الله عليه وسلم :

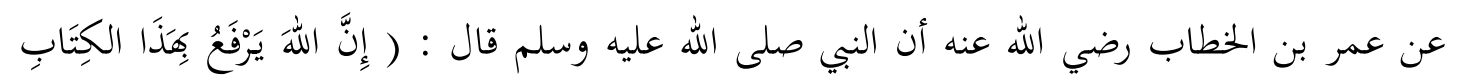

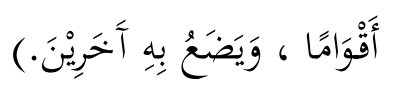

ع. حفاظ القرآن لهم درجة عالية في الجنة لقوله النبي صلى الله عليه وسلم :

\footnotetext{
'Smith, Huston and Cyril Glasse, Ensiklopedi Islam, (Jakarta: Raja Grafindo Persada, 1999 ), hal. rYV.

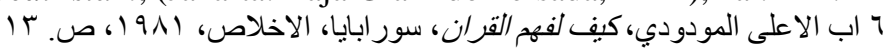

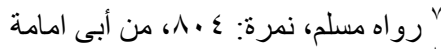

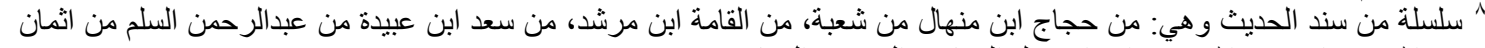

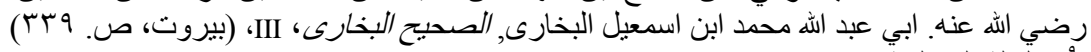

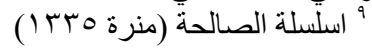


عن عبدالله بن عمرو بن العاص رضي الله عنهما ، قال : قال رسول الله )) : يُقَّالُ لِصَّاحِبِ القُرْآنِ

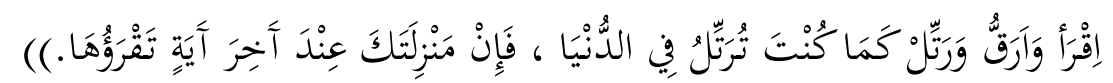

$$
\text { في حديث آخر قال النبي صلى الله عليه وسلم : }
$$

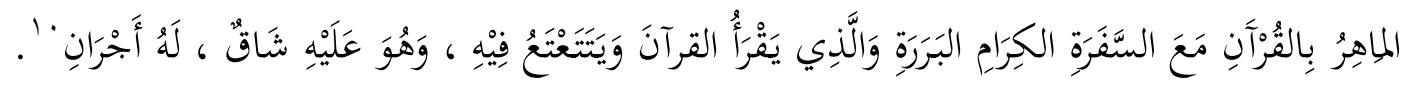

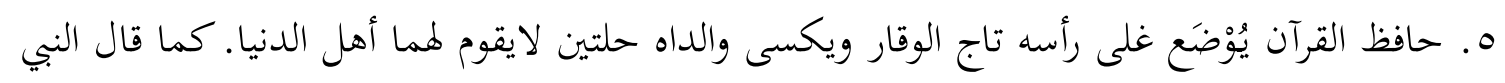

$$
\text { صلى الله عليه وسلم في حديثه الشريف. }
$$

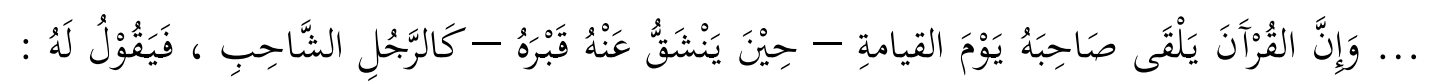

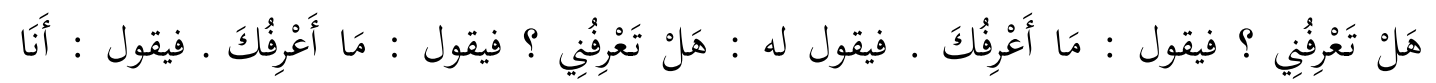

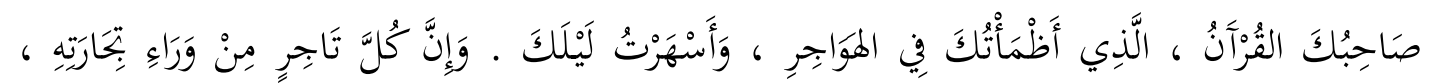

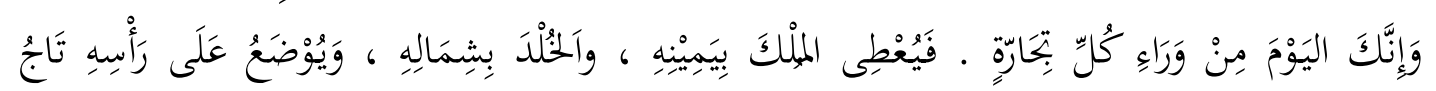

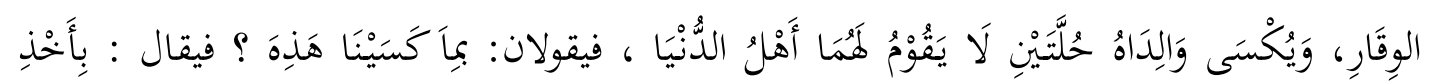

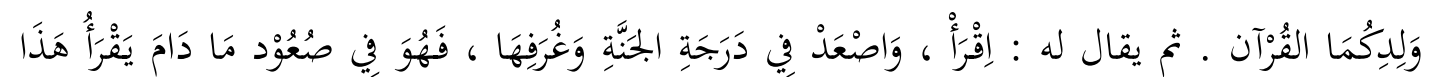

ج . حفظ القرآن عصمة لمسلم في الدنيا والآخرة، كما قال النبي صلى الله عليه وسلم :

عن أبي الدرداء رضي الله عنه أن رسول الله صلى الله عليه وسلم قال : (( مَنْ حَفَظَ عَشْرَ آيَاتٍِ مِنْ

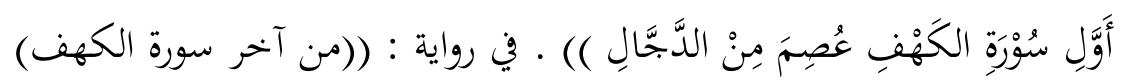

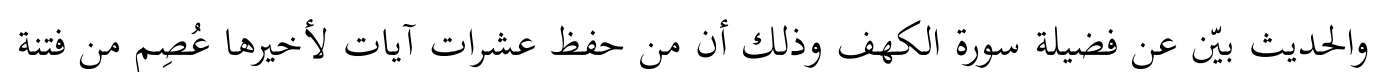
الدنيا الأكبر وهي فتنة الدجال. فلذا من حفظ القرآن ولو آيات عصمه الله وحفظه وأبخاه من أشرار الناس، ولاسيما إذ أنه حفظ القرآن ثلاثين جزءا كاملا.

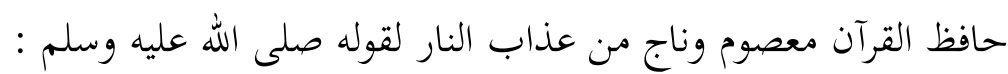

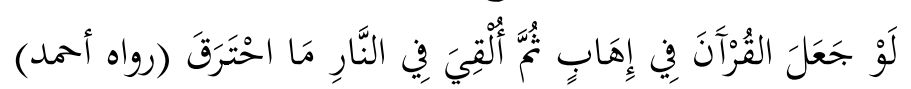

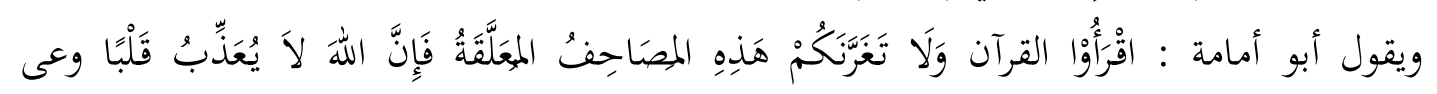

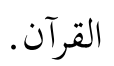

$$
\text { في حديث آخر قال النبي صلى الله عليه وسلم : }
$$

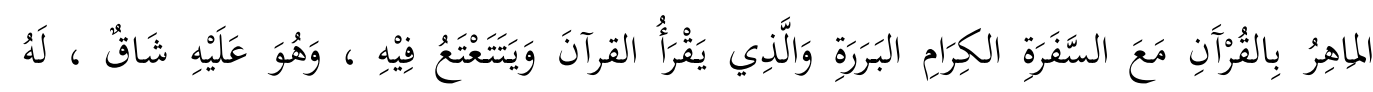

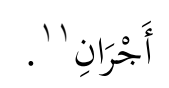

$$
\text { " "رواه مسلم، نمرة ل91 Vمن عائشة }
$$




\section{حافظ القرآن معصوم وناج من عذاب النار لقوله صلى الله عليه وسلم :

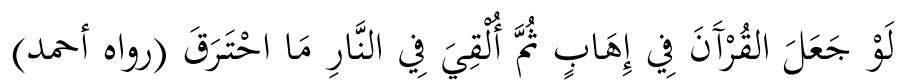

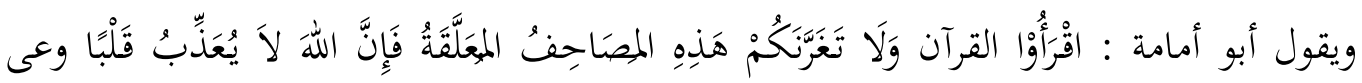

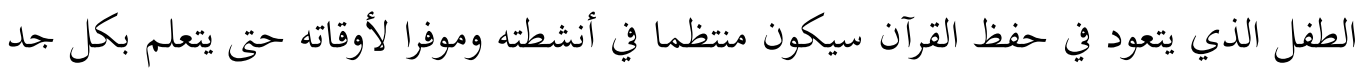

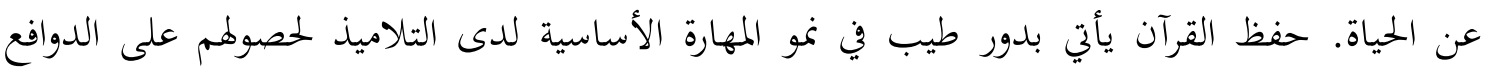

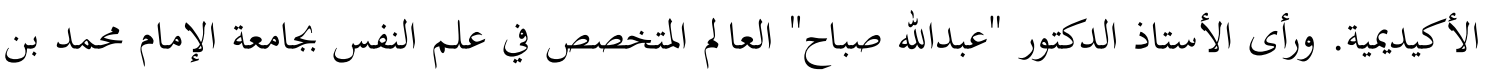

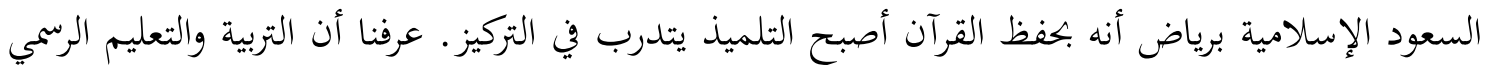

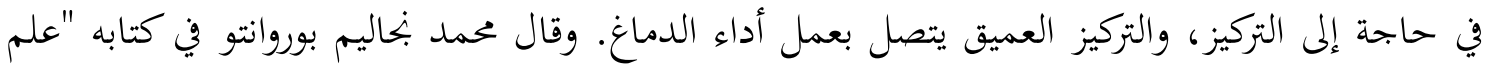

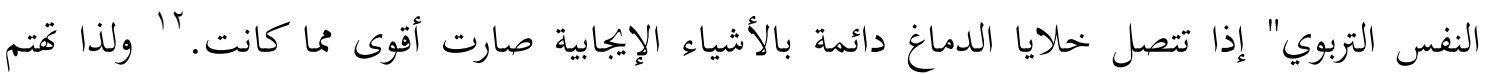

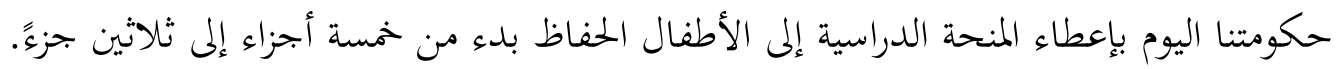

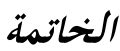

الاستنباط

تم الاستنباط معتمدا على مطالعة البحث وتحليل نتيجته المستعرضة في الأبواب السابقة كما يلي : ا ـ في مرحلة الإعداد، كان المعلمون يعدون إعداد التدريس ويصنعون القصة المتقاطعة.

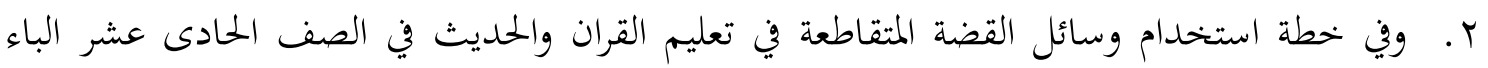

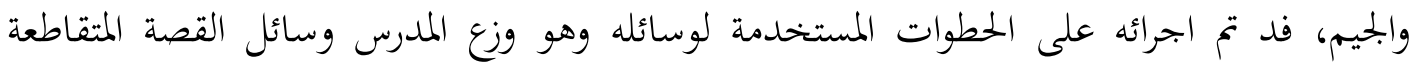

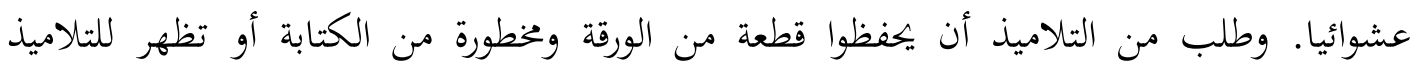

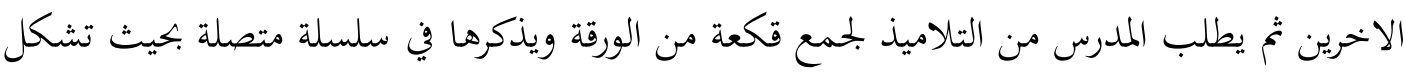

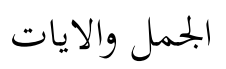

r. وفي النشاط النهائي تقييم المدرس نتائج التعلم من خلال الحفظ جميع الايات متصلة وكاملة ثم

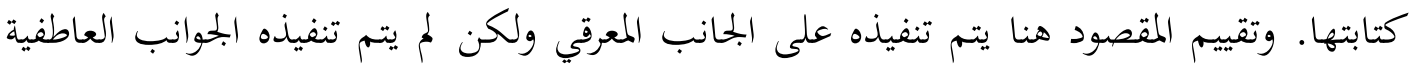
والنفسية.

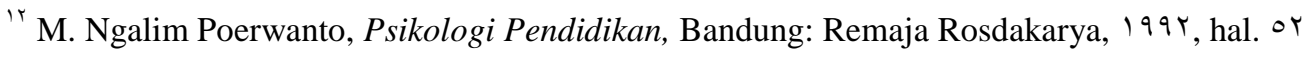




\section{المواجع والمصادر}

Abu A'la al-Maududi, Bagaimana Memahami Al-Qur'an, Surabaya: Al-Ikhlas, 1911

Abu Ya'la Kurnaedi, Tajwid Lengkap Asy-Syafi'I, Jakarta, Pustaka Imam Syafi'I, Y • I

Ahmad Syadzali dan A. Rofiq, Ulumul Qur'an, Bandung: Pustaka Setia, r.. ฯ

Arief S.Sadiman,dkk, Media Pendidikan: Pengertian, Pengembangan, dan pemanfaatannya, Jakarta: PT Raja grafindo Persada, Y.।l

Ashiddiqy, TM, Hasbi, Sejarah dan Pengantar Ilmu Al-Qur'an dan Tafsir, Semarang: Pustaka Rizqi Putra,,$\ldots$

Asnawir dan Basyirudin Usman, Media Pembelajaran, Jakarta: Ciputat Pers, $\uparrow \cdots r$

Azhar Arsyad,Dr, Bahasa Arab dan metode pengajarannya,Yogyakarta, Pustaka Pelajar, $\uparrow \ldots r$

Budiningsih, Asri, Belajar dan Pembelajaran, Jakarta: Asdi Mahasatya, r...

Depag, RI, GBPP Qur'an Hadits MTs 199 , Dirjen Kelembagaan Agama Islam Depag RI, $199 \leqslant / 1990$

Departemen Pendidikan Nasional, Kamus Besar Bahasa Indonesia, Edisi III, Jakarta: Balai Pustaka, r..r

Djamarah, Syaiful Bahri, dan Aswan Zain, Strategi Belajar Mengajar Jakarta: Rineka Cipta, r.. $\uparrow$, Cet $r$

Hadi,Sutrisno, Metodologi Research I, Yogyakarta: Andi, ${ }_{\text {... }}$

Hamalik, Oemar, Perencanaan Pengajaran Berdasarkan Pendekatan Sistem, Jakarta: Bumi Aksara,, ...

Hamdani, Strategi Belajar Mengajar, Bandung: CV. Pustaka Setia, r. 11

Hasbi TM Ashiddiqy, Sejarah dan Pengantar Ilmu Al-Qur'an dan Tafsir, Semarang: Pustaka Rizqy Putra,,$\ldots$

H.M.Yunus, Prof, AtTarbiyah wa Ta'lim, Matba'ah, Padang Panjang, 19 1

Ichwan, Mohammad Nor, Studi Ilmu Hadits, Semarang: Rasail Media Group, $19 \wedge$ v

Latifah, Effektifitas penggunaan media strip story untuk meningkatkan kemampuan membaca di Pondok Pesantren Darussalam Sukalila Jatibarang Indramayu Jawa Barat, Bandung, $r+11$

Maghfirotul Khasanah, Upaya Peningkatkan Hafalan Siswa dengan Menggunakan Media Pembelajaran Strip Story pada Mata Pelajaran AlQur'an Al-Hadits, Semarang, r. 11 
M. Ngalim Poerwanto, Psikologi Pendidikan, Bandung: Remaja Rosdakarya, 199 Ү

Raghib As-Sirjani, Cara Cerdas Menghafal Al-Qur'an, Solo: Aqwam, r...

Renda Saputri, Eksperimentasi Media Strip Story Terhadap Pemahaman Teks Bahasa Arab Siswa Kelas VIII C MTs Mu'allimin Parakan Temanggung, Yogyakarta, Y • I ₹

Riyadh, Saad, Mendidik Anak Cinta Al-Qur'an, Sukoharjo: Insan Kamil, ץ...

Sayid Sabiq, Aqidah Islam, terj. Abdul Rathomil, cet. ke- ₹, Bandung: Diponegoro, 1910

Smith, Huston and Cyril Glasse, Ensiklopedi Islam, Jakarta: Raja Grafindo Persada, 1999

Sudjana, Nana, Penelitian dan Pendidikan, Bandung: Sinar Baru, 1990 